\title{
UNA ARQUITECTURA PARA EL SILENCIO. EL TANATORIO DEL CEMENTERIO DE BOISACA DE SANTIAGO DE COMPOSTELA
}

Data recepción: 2011/05/15

Data aceptación: 2011/11/23

Contacto autor: enrique.fernandez.castineiras@usc.es
Enrique Fernández Castiñeiras

Universidade de Santiago de Compostela

\section{RESUMEN}

En este artículo se pone de relieve la actitud que la sociedad de hoy en día adopta ante la muerte y como esta se refleja en los propios espacios a ella destinados. Alfredo Varela Nogueira propone en el tanatorio de Boisaca una arquitectura basada en la mutua potenciación de los espacios, buscando un enfoque funcional, en el que se resalta la expresividad de los materiales, mostrándolos tal y como son, sin disfrazarlos ni ocultarlos, a través de unas formas puras, de la definición de los espacios y de los símbolos, y en el que la luz va a desempeñar un papel primordial.

Palabras clave: Arquitectura, siglo XXI, tanatorio, Varela Nogueira, Santiago de Compostela

\section{ABSTRACT}

This article analyses modern-day attitudes towards death and how these are reflected in the spaces devoted to it. In designing the Boisaca morgue, Alfredo Varela Nogueira has constructed a building based on the mutual promotion of spaces, adopting a functional approach that puts the emphasis on the expressive nature of the materials, displaying them exactly as they are without disguising or concealing them, and doing so through purity of form and the defining of spaces and symbols, while also allowing light to play a fundamental role.

Keywords: Architecture, 19th century, morgue, Varela Nogueira, Santiago de Compostela

"... No morimos porque estemos enfermos sino porque estamos vivos ..."

M. Montaigne

\section{El discurso de la muerte}

La muerte se define de múltiples formas, y los diccionarios lo hacen como "el cese de la vida", "la ausencia de la vida", "el fin de la vida humana",...; por ello cuando hablamos de la muerte lo estamos haciendo también de la vida. Son los dos extremos del ciclo vital ${ }^{1}$. En realidad definirla no es algo sencillo, ya que es un concepto multívoco; la muerte es plural en su esencia y en sus maneras de morir, incluso hay que diferenciar las varias muertes físico-biológicas pues no se sitúan en el mismo plano para los humanos y para los animales; además "la especie humana es la única para la que la muerte está presente durante toda su vida, la única que acompaña a la muerte de un ritual funerario, la única que cree en la supervivencia o en la resurrección de los muertos" ${ }^{\prime 3}$.

Hasta hace muy pocos años la muerte estaba muy presente en la vida diaria ${ }^{4}$, lo que muy probablemente en el caso gallego venía motivado por nuestra vinculación con la tierra ${ }^{5}$. Sin embargo, tras el Concilio Vaticano II (1962-65) se configura un nuevo ritual que va a romper 
con aquella larga tradición en la que se insistía sobre la buena muerte y en su preparación a través de la extremaunción y el viático, así como con la celebración de las misas de difuntos. Los rituales se despojan de su carga emotiva, se busca la discreción y el duelo silencioso; incluso podemos llegar a decir que se vive un proceso de "secularización"

Se inicia el abandono de costumbres ${ }^{7}$ como la presencia de un importante número de sacerdotes oficiando el ceremonial del funeral, algo con lo que se buscaba remarcar el estatus social de la familia del fallecido; el uso del luto; de los largos velatorios en la casa del difunto; de las comidas funerarias; ; de que los fallecimientos no se produzcan en los domicilios sino que mayoritariamente tengan lugar en los centros hospitalarios, lo que en buena parte viene obligado por la reducción de las dimensiones de nuestras viviendas; etc. Un proceso que se inicia apartando al moribundo en sus últimos momentos de su entorno, de los seres con los que transcurrió gran parte de su existencia, de las muestras de cariño ${ }^{9}$, para ubicarlo en las frías salas de un hospital conectado a una máquina por medio de un sinfín de tubos, y que culmina con la aparición de los tanatorios. Estos van a "gestionar" la muerte de manera totalmente distinta a como se había venido haciendo, pues ahora el muerto deja de ser el "objetivo" para serlo el vivo, al que se le proporciona mayor comodidad e intimidad; además, como señala Juan Luis Pintos, el tanatorio no sólo es un "servicio" que la comunidad necesita, sino que también es una "empresa" que obtiene de su servicio un determinado beneficio económico ${ }^{10}$, prueba de lo que se dice es el amplio número de páginas webs que nos encontramos en Internet.

Este cambio de actitud no solo está repercutiendo en todos los aspectos relacionados con los rituales fúnebres, cada vez más impersonales como decíamos, y desprovistos de significado, sino que también lo está haciendo en los propios espacios de la muerte, cada vez más seriados, más privados de carga emotiva, sin el espíritu evocador y la memoria de antaño.

El paulatino proceso de masificación y secularización de la sociedad ha transforma- do los cementerios en aparcamientos de difuntos sometidos a las leyes del máximo aprovechamiento y de la vulgaridad repetitiva. Los deudos de los fallecidos intentan paliar esta situación mediante patéticos alardes de lápidas estridentes y florilegios artificiales. La consecuencia es que el cementerio en la actualidad no es más que un lugar para olvidar a los muertos"1,

al tiempo que una representación a escala de la ciudad de los vivos con sus mismos problemas de conservación, saturación y especulación.

\section{Arquitectura para los muertos: el tanatorio}

El muerto siempre será un ausente, y la muerte una ausencia insoportable que, para sobrellevarla, se pretende llenar con una imagen. Por eso las sociedades han ligado a sus muertos con un lugar determinante, y lo han provisto, mediante la imagen, de un "cuerpo inmortal": un cuerpo simbólico con el que pueden socializarse nuevamente, en tanto que el cuerpo mortal se disuelva en la nada'2, en el cementerio, que si bien es cierto que en un primer momento compartió vecindad con el espacio de los vivos y generalmente próximo a la iglesia (Fig.1), lo que hacía que la muerte estuviese integrada en la vida cotidiana, con el paso del tiempo termina por verse desplazado fuera de los núcleos urbanos ${ }^{13}$, iniciándose así el proceso irreversible de alejar de sí a sus difuntos y lo que algunos autores denominaron "el exilio de los muertos"14, y lo que motiva que los antiguos lugares de enterramiento terminasen siendo borrados o convertidos en lugares de esparcimiento, o bien se conserven con la particularidad de que los enterramientos más recientes daten de hace varias décadas, prueba evidente de la implantación de las nuevas costumbres ${ }^{15}$.

El tanatorio, por supuesto, no es un cementerio aunque su nombre podría sugerirlo - la palabra tanatorio proviene del término griego tanatos, que quiere decir muerte-, y, lógicamente, tampoco es un crematorio; es un lugar a medio camino entre ambos ya que es un espacio en el que el cadáver permanece a la espera de ser incinerado o inhumado. 


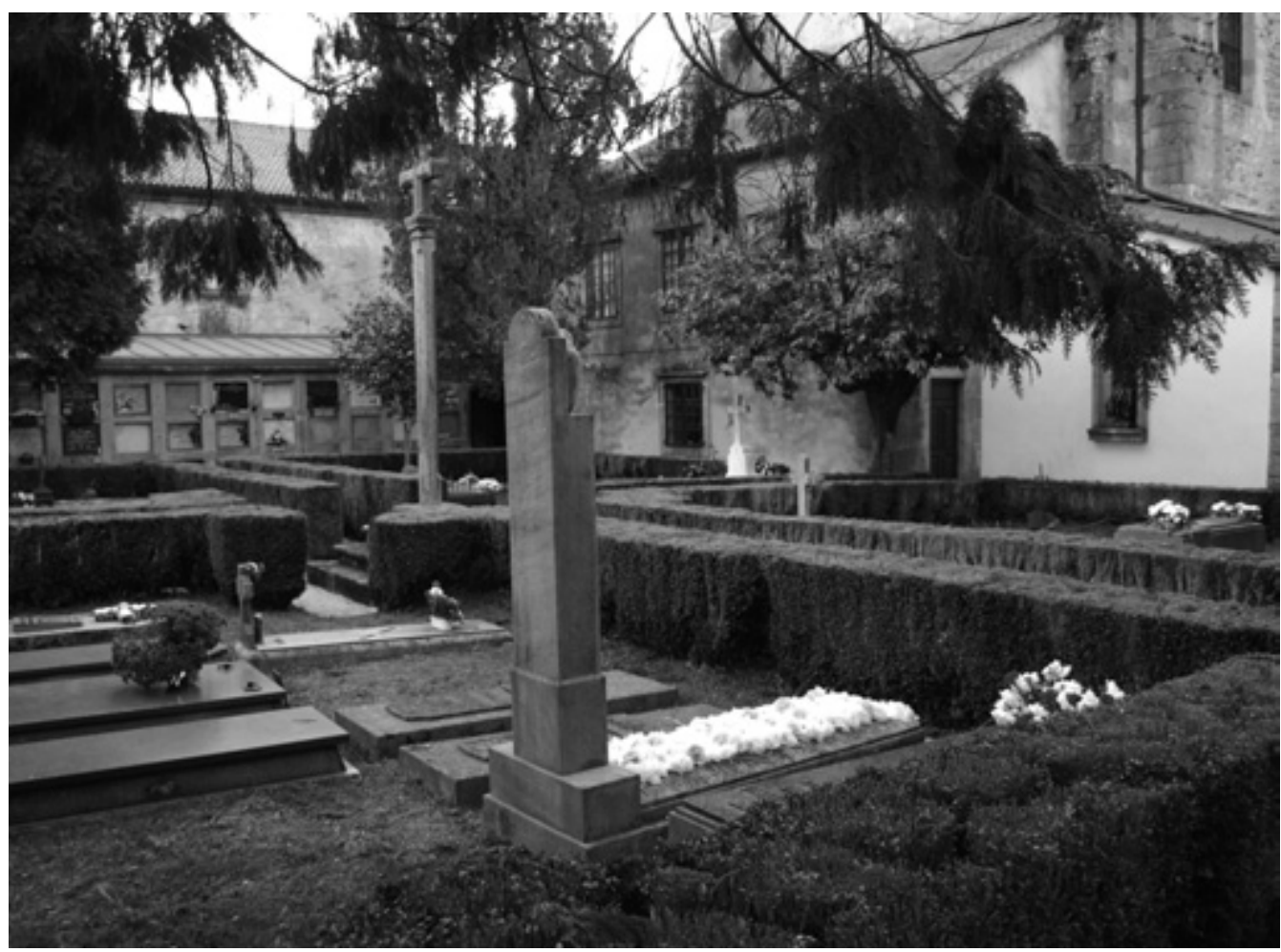

Fig. 1. Vista parcial del cementerio de la Cofradía de Nuestra Señora del Rosario. Santiago de Compostela.

Su aparición en nuestro país cabe datarlo a mediados de la década de $1970^{16}$, y viene justificado por varios factores: el número creciente de fallecimientos en los hospitales y no en los domicilios; la disgregación geográfica de las familias y la considerable disminución del tamaño de las viviendas, razones que van a dificultar el tradicional velatorio en el domicilio del fallecido. Pero aquellos tanatorios construidos en las últimas décadas del siglo XX — carentes de servicios y que no tenían una buena imagen, lo que en buena medida venía dado por el hecho de ser o bien unos espacios lúgubres o bien anodinos, unos desiertos de hormigón en los que parecía que estaba proscrita la presencia de cualquier vestigio de vida por lo que no localizamos en ellos ni siquiera una brizna de hierba-, poco tienen que ver con los actuales que además de estar pensados para proporcionarle a los familiares del difunto el grado de intimidad que la "despedida" requiere, están dotados de las dependencias necesarias para atender a las múltiples necesidades que ahora se demandan. De ahí la aparición de una nueva tipología que modifica la anticuada visión de la muerte y que persigue ser más que un simple velatorio.

La muerte hoy es un negocio que llega a mover importantes sumas de dinero, prueba de este carácter que ahora tiene es el hecho de que, como señala Juan Luis Pintos, en lugar de hablarse de "fallecidos", "difuntos", etc., se utiliza el término de "usuarios"17, esto, lógicamente, obliga a atender aquellas necesidades que la sociedad demanda, y una de ellas es el de la creación de espacios preparados para la incineración, un sistema en pleno auge frente a los enterramientos, lo que, inevitablemente, obliga a la creación de una serie de estancias específicas 


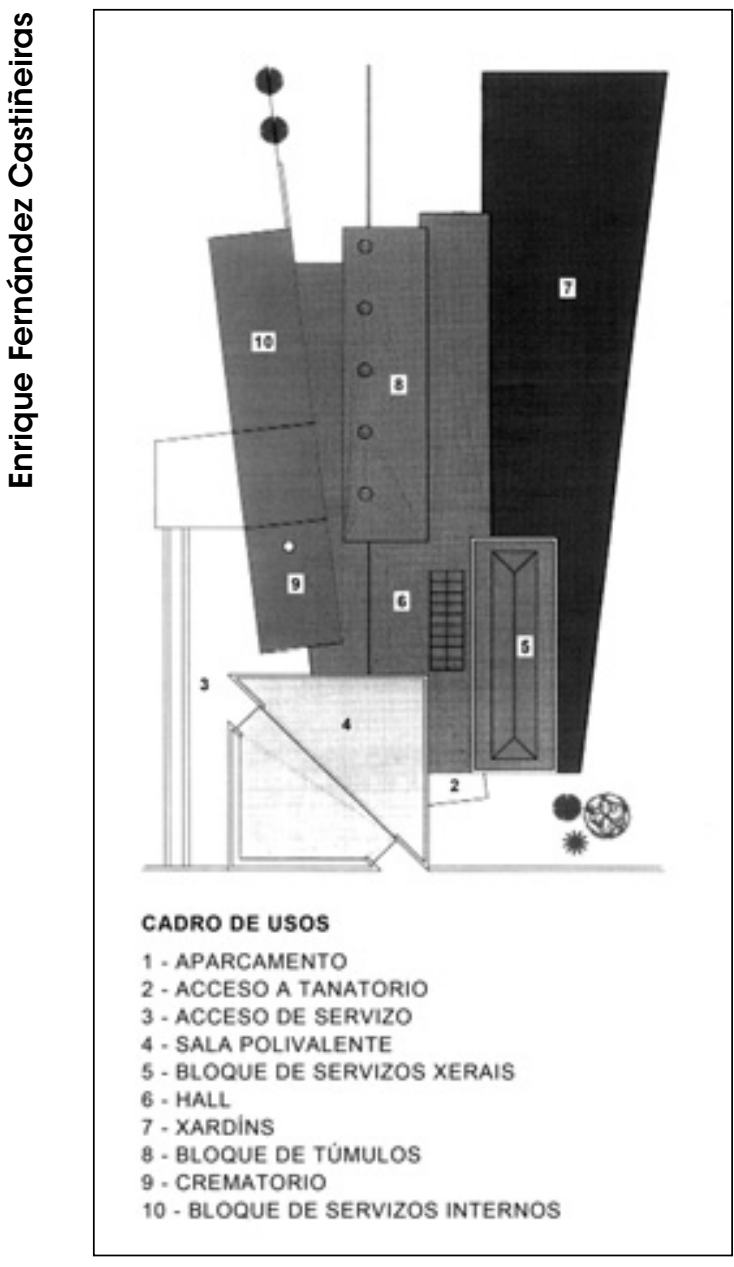

tanto destinadas a llevar a cabo el proceso como para que familiares y amigos que hayan elegido esta modalidad puedan esperar y recoger las cenizas del ser querido. No podemos olvidar que en los antiguos crematorios la despedida del difunto se producía en la iglesia parroquial ya que el cadáver, una vez celebrada la ceremonia religiosa, era conducido al horno crematorio. Esto no hace más que confirmar el sentimiento y la creciente angustia del hombre de hoy en día frente a la muerte, lo que no hace más que distanciarla del ámbito de lo cotidiano, llegándose a ensombrecer el momento de la

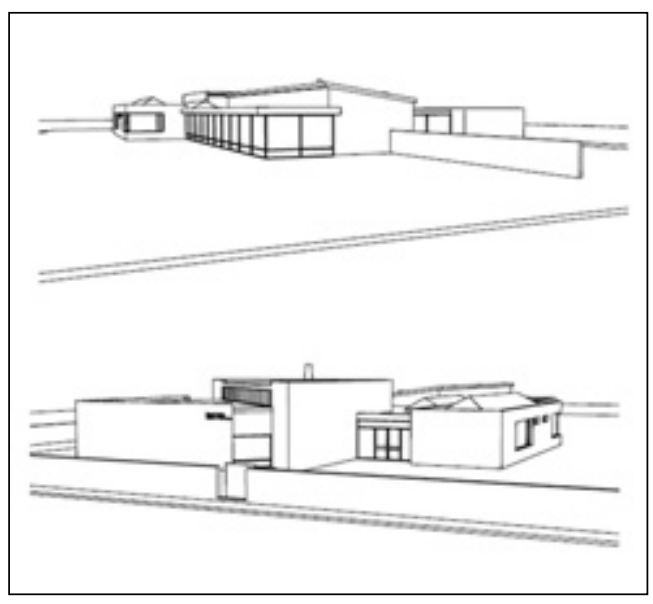

Fig. 2. Tanatorio de Boisaca. Santiago de Compostela. Planta y alzados.

muerte, el velatorio y el entierro para que esta situación no interrumpa el ritmo habitual de la vida. El duelo ahora se queda en lo más íntimo de la persona pues se considera que es algo muy personal y que no debe exteriorizarse.

El tanatorio bajo ningún concepto puede ser considerado un edificio eclesiástico, es un espacio laico, por lo que tiene que estar al servicio de todas las creencias religiosas sin excluir a ninguna, una condición que muy probablemente le vino impuesta al arquitecto en el contrato, pero también tenemos que juzgarlo como un espacio religioso ya que es un lugar vinculado a los últi- 


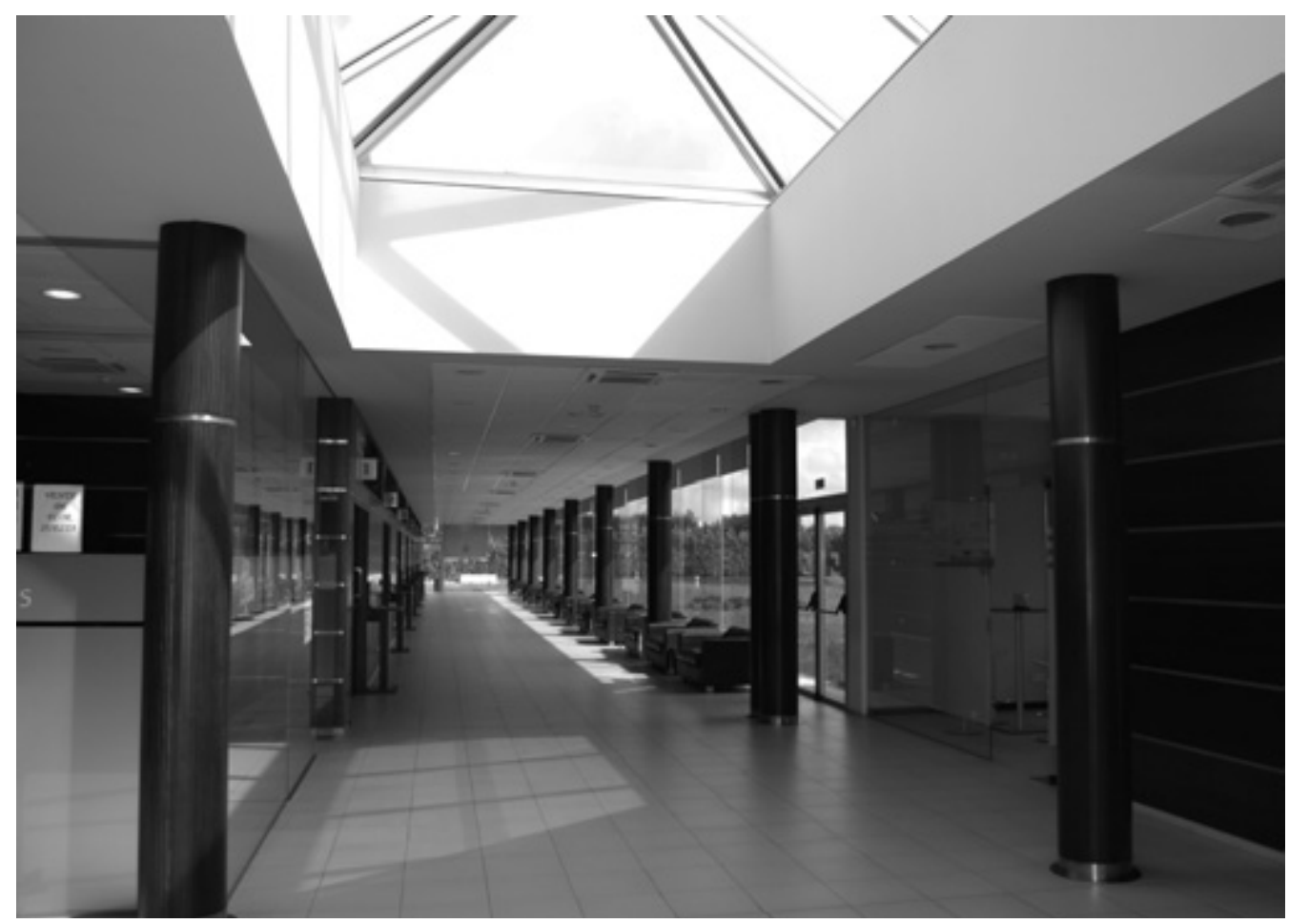

Fig. 3. Interior. Tanatorio de Boisaca.

mos ritos de la vida humana y al dolor de los asistentes al duelo, y hablar de ese dolor es acercarse al significado de los valores religiosos, pues el valor religioso está profundamente relacionado con el valor emocional humano de la vida.

El tanatorio de Boisaca de Santiago de Compostela, construido en el 2004-05, es una obra en la que el arquitecto Alfredo Varela Nogueira ${ }^{18}$, dejándose llevar por los principios de sencillez y de "utilidad", prescinde de los elementos ornamentales y proyecta un conjunto constituido por varios espacios bien diferenciados y de proporcionadas líneas rectangulares (Fig. 2). Una arquitectura amable, pero no fría, y, por supuesto, elegante, logrando con la concepción que hace del espacio, la proporcionalidad de los elementos, la pureza de sus líneas, la armonía de sus formas, la interrelación de sus volúmenes, comunicarnos un sentimiento de recogimiento, pero no de tristeza, lo más apropiado para este espacio que sirve de transición entre la vida y la muerte; por ello, las únicas visiones desde el interior son las del cielo y las de un pequeño jardín interior (Fig. 3). Muy probablemente sea producto de mi imaginación, pero aseguraría que nada hay en él que nos traiga recuerdos tanáticos, más bien hablaría de evocaciones a la vida, lo que ya no sé es si el autor pretendía con ello hablarnos de la vida del "más allá".

Se levanta en una parcela próxima al cementerio y de $4.609 \mathrm{~m}^{2}$, de forma trapezoidal y limitada por la rúa das Mulas, a la que da su fachada, y por dos vías con orientación sureste y noroeste respectivamente - el terreno tiene un 


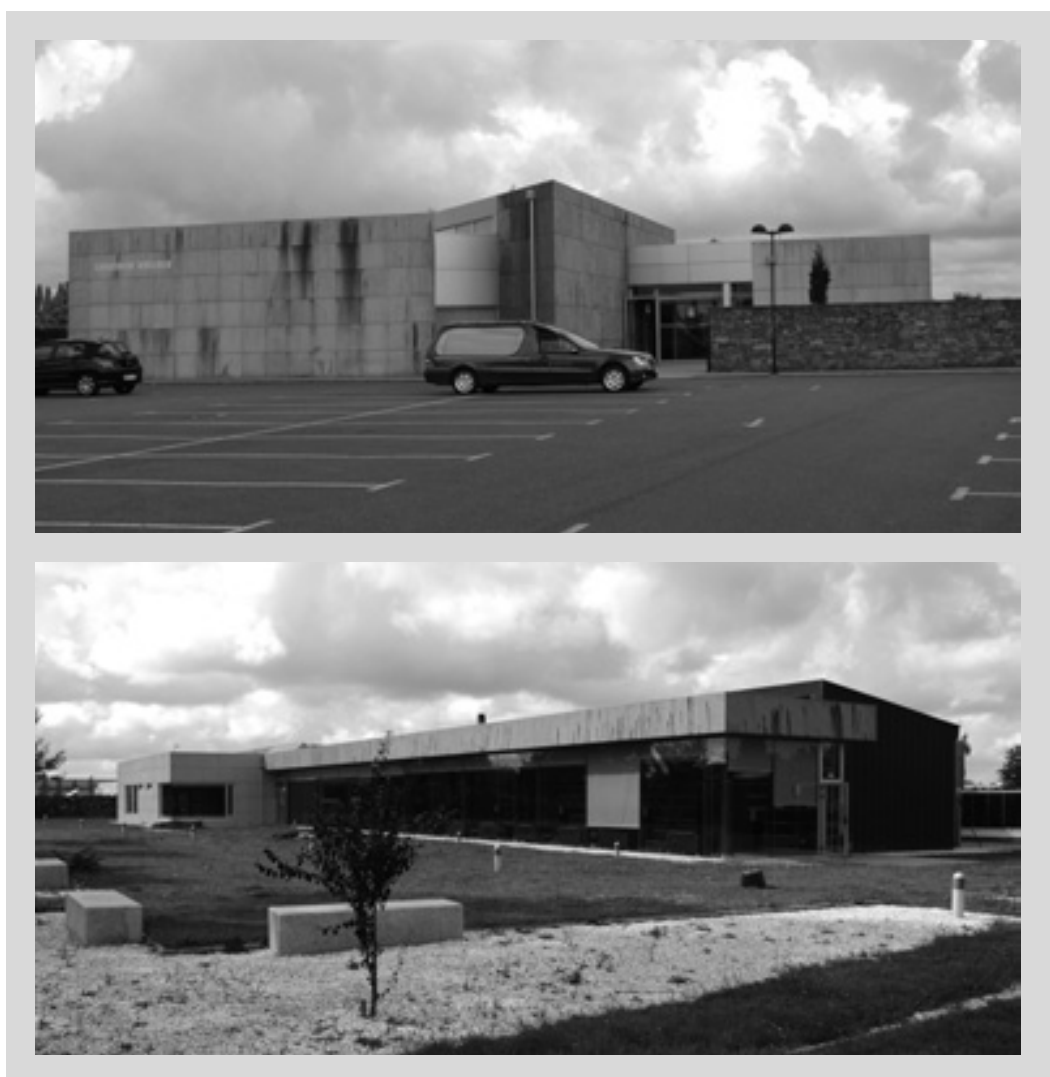

Fig. 4. Tanatorio de Boisaca.

frente de $47 \mathrm{~m}$, aproximadamente, mientras que en la parte posterior llega a los 57, y alcanza un fondo de unos $89 \mathrm{~m}$ - ajustándose al Plan Especial para el desenvolvimiento del Sistema General C $-1^{19}$.

El arquitecto no lo concibe como un "bunker" en el que protegerse para ahogar el dolor, tampoco sigue esos modelos demasiado fríos y hospitalarios que caracterizan a muchas de estas construcciones, sino que su objetivo primordial fue el relacionarlo con una arquitectura más doméstica, y por lo tanto más amable.

Su aspecto externo (Fig. 4) para nada indica la función a la que está destinado, y así, frente a lo que viene siendo una característica arquitectónica de un buen número de estos edificios, el arquitecto enmascara su chimenea, el "incensario de la muerte", el símbolo visible de las prácticas de cremación, muy probablemente porque es consciente de que su presencia socialmente es considerada negativa ya que se rechaza la visión del humo. De ahí que el resultado sea un edificio que no llama excesivamente la atención, claro que tampoco tendría porque hacerlo pues su finalidad no es otra que acoger el dolor por la pérdida y despedida del ser querido al tiempo que reconfortarnos con una esperanza, y cabe reconocer que en él todo contribuye a lograr el efecto deseado con esa fusión entre arquitectura y paisaje, jlástima que la zona ajardinada integrada en el edificio no este hoy más en consonancia con lo que debie- 


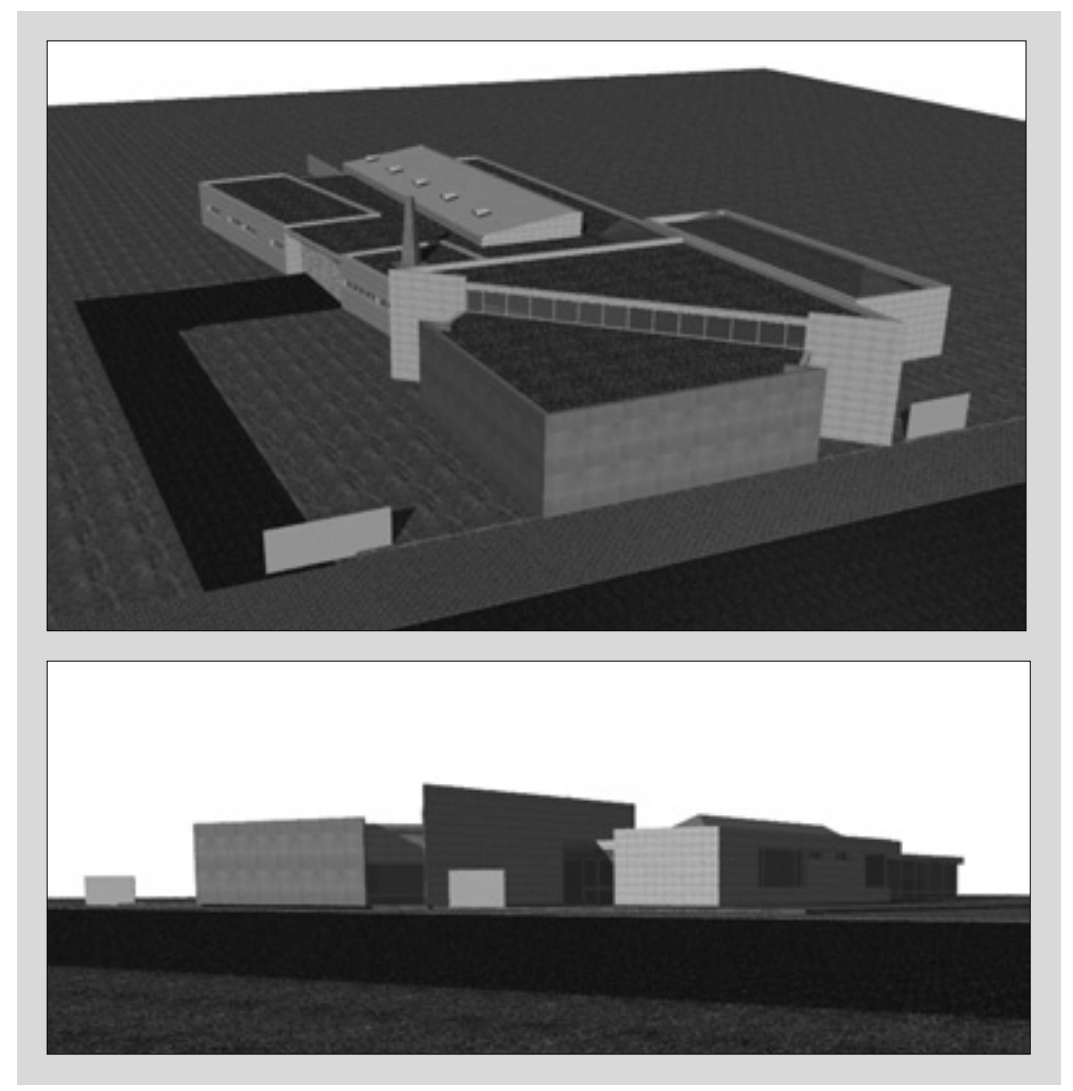

Fig. 5. Tanatorio de Boisaca. Simulación gráfica.

ra simbolizar, o que la explanada de acceso sea un desnudo y desangelado aparcamiento!; claro que esto ya no es culpa del autor.

El proyecto se plantea en una sola planta de $1.506,87 \mathrm{~m}^{2}$ útiles y de 1.630,91 $\mathrm{m}^{2}$ construidos, valiéndose para ello de varios espacios volumétricos bien diferenciados y con una organización que se refleja en el exterior (Fig. 5), y que acogen por un lado: una sala polivalente, que terminaría por convertirse en la capilla, la zona de administración, la sala de exposición de ataúdes, aseos, cafetería, floristería y servicios generales, junto a las tradicionales salas de vigilia: los túmulos y siete salas velatorio —en un primer momento solo se había pensado en cinco-; unos espacios que están entendidos como pequeños apartamentos, mejor dicho, "moradas para el tránsito", con tres dependencias: una para depositar al féretro, la otra para velarlo —el mobiliario de cada una de estas siete salas es, por su color, todo un recuerdo al arte del neoplasticismo- y un pequeño aseo. La zona de túmulos queda flanqueada de un lado por el pasillo de acceso que se abre hacia los jardines y en el lado opuesto, configurando otro gran volumen rectangular y dispuesto en un ligero ángulo, el área de servicios internos: la sala de cremación, con un horno prefabricado con las técnicas más avanzadas en este tipo de componentes; la sala de tanatopraxia y tanatoestética, un lugar dotado del equipamiento necesario en este tipo de instalaciones y donde 
los técnicos reparan y preparan el cadáver del difunto, mediante retoques estéticos y técnicas de conservación de los cuerpos (Fig. 6); despachos, una sala de administración con acceso a un expositor de ataúdes, aseos para el personal y un almacén; así como el acceso de los vehículos, ambulancias y vehículos fúnebres.

El tanatorio, por consiguiente, está definido por dos zonas perfectamente diferenciadas con funciones específicas y procurándose en todo momento que se pueda perturbar el recogimiento de los familiares y amigos del fallecido, por ello, la edificación se plantea con dos entradas que se disponen en los extremos de la fachada, algo que nos trae evocaciones con el hacer de Rafael Moneo en la catedral de Nuestra Señora de los Ángeles ${ }^{20}$; claro que, si partimos de un riguroso simbolismo, podríamos decir que este hecho se opone al ritual eclesiástico tradicional, pues en la iglesia, tanto cuando nos bautizamos como cuando celebramos un funeral, se entra y se sale por la misma puerta, $y$, sin embargo, la propuesta que aquí se hace es de un gran acierto ya que sirve para favorecer las incineraciones, al tiempo que se evita ese malestar que puede producirse en algunas personas ante los aspectos técnicos y rituales de la cremación, aunque ello vaya en contra de las costumbres religiosas.

Esta doble entrada permite, además, que la organización interna esté perfectamente defini$\mathrm{da}$, con un buen aprovechamiento y con la creación de espacios con las condiciones de privacidad necesarias en tales momentos. El vestíbulo de entrada para el publico, punto de encuentro de los usuarios y que actúa a manera de los antiguos atrios, da paso a un recinto que nos permite abarcar la totalidad de la zona de vigilia, y cuyo trazado parece configurado con la idea de prolongar el espacio de la calle como un recorrido hacia el interior del edificio, y, merced a utilizar como soporte unos pilares circulares exentos, presenta todo el muro sur desmaterializado y convertido en una generosa lámina de cristal sin perfilería y contrafuertes de este mismo material de dos centímetros de grosor, que permite abrirse a un jardín, cubierto de césped limpio de vegetación, haciendo así que espacio interior y paisaje sean considerados como un todo (Fig. 7).
A la luz que entra a raudales a través del acristalamiento de esa fachada se suma la que, de manera cenital, penetra a través de una fisura central acristalada practicada en la cubierta; es como si el espacio de la ausencia nos abrazase para que nos uniésemos a él, pero solo a través de la vista y la mente, de esta manera se transmuta el espacio cualitativo del que queda a nuestra izquierda, diferenciando así el de los vivos del de los muertos; un concepto perfectamente asimilado por el arquitecto. Una luz natural que también es transmitida a las salas en las que es depositado el cadáver a través de un lucernario circular central cenital ${ }^{21}$ (Fig. 8), que así dirigida sobre la caja mortuoria sirve para acentuar la alegoría de la vida: "Yo soy la luz del mundo; el que me sigue no anda en tinieblas, sino que tendrá luz de vida"22. Así, en este recinto se entiende a la perfección lo que significa nuestra condición de transeúntes en este mundo.

Alfredo Varela nos propone con esta construcción una arquitectura racionalizada que lleva a una creación artística ${ }^{23}$ pues realiza un programa, selecciona unas técnicas y elige una estética, además de la disposición de espacios, elementos y formas de expresión, texturas, funciones y usos del color y la mayor o menor presencia de la luz; de ahí que el arquitecto además de presentarse como un técnico con medidas, equilibrio de las cargas, elección de los materiales valorando la resistencia de los mismos, etc., también deja que aflore su intuición, su sensibilidad, a través de las peculiaridades cualitativas, cromáticas, de textura, etc. ${ }^{24}$, de los materiales empleados que se refleja en unos resultados estéticos concretos, y que es con lo que el espectador se queda: la belleza plástica del conjunto, algo que no siempre se persigue ya que la misión fundamental del arquitecto es tratar de solucionar las necesidades efectivas y reales del hombre ${ }^{25}$.

\subsection{Peculiaridades constructivas}

El proyecto arquitectónico sigue los planteamientos vigentes en la arquitectura contemporánea, aunque planteando nuevas vías a la innovación y el desarrollo del pensamiento arquitectónico. El respeto que el arquitecto siente por los 


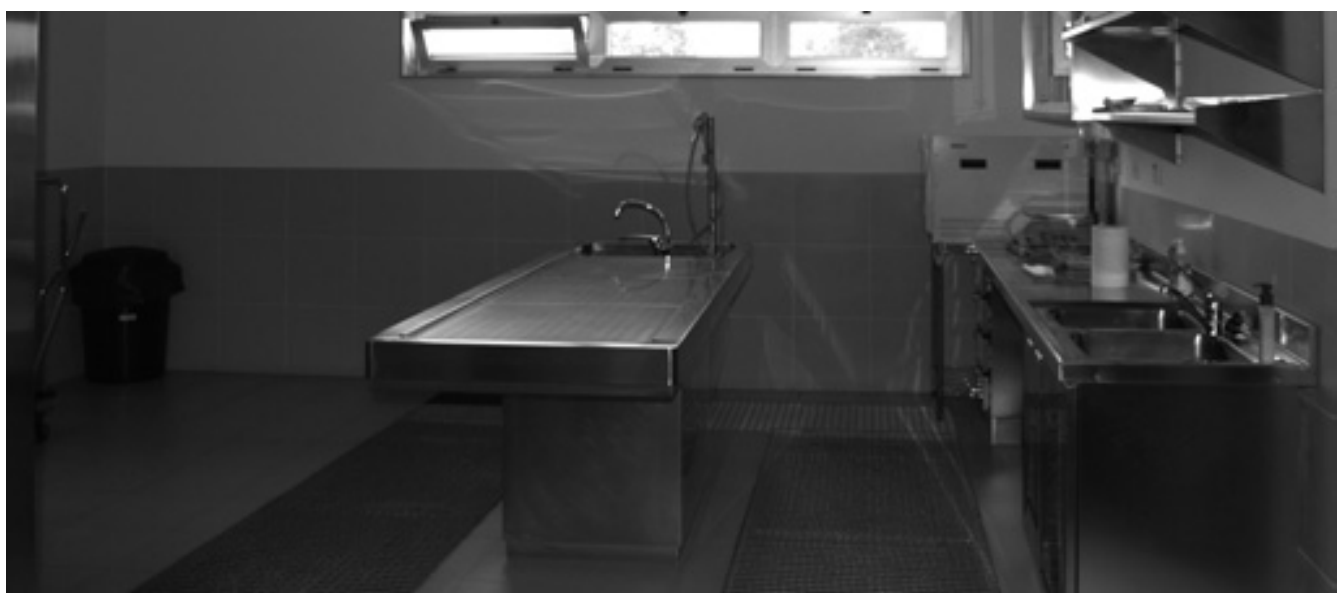

Fig. 6. Sala de tanatopraxia. Tanatorio de Boisaca.

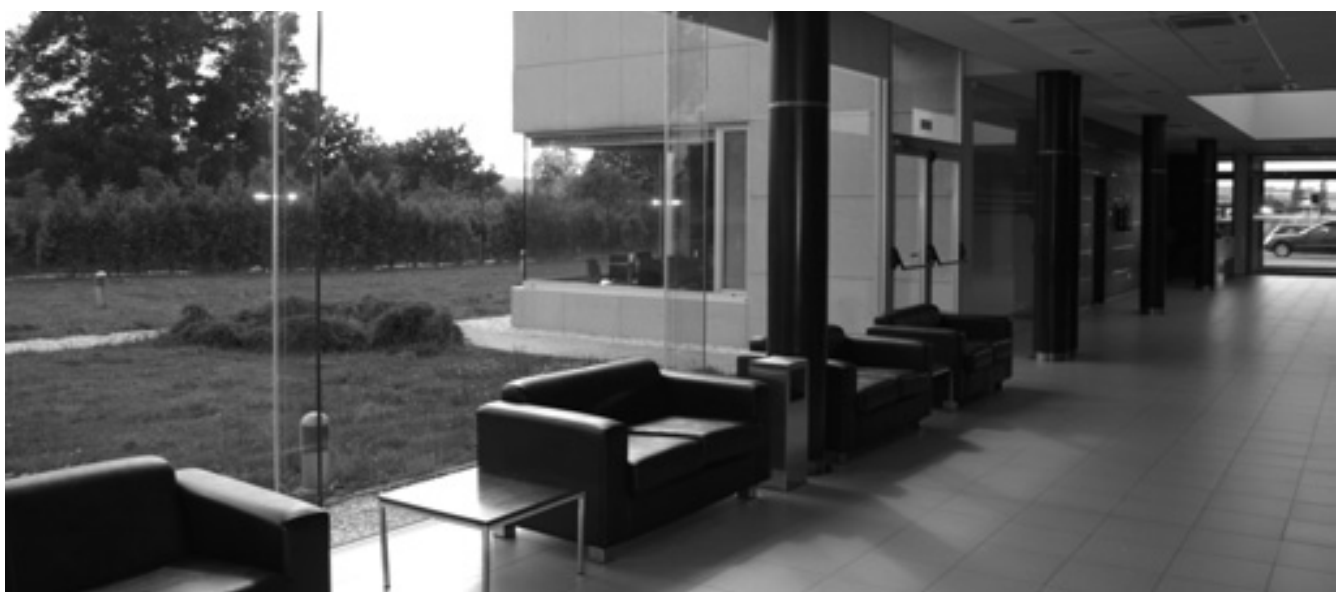

Fig. 7. Vista del jardín. Tanatorio de Boisaca.

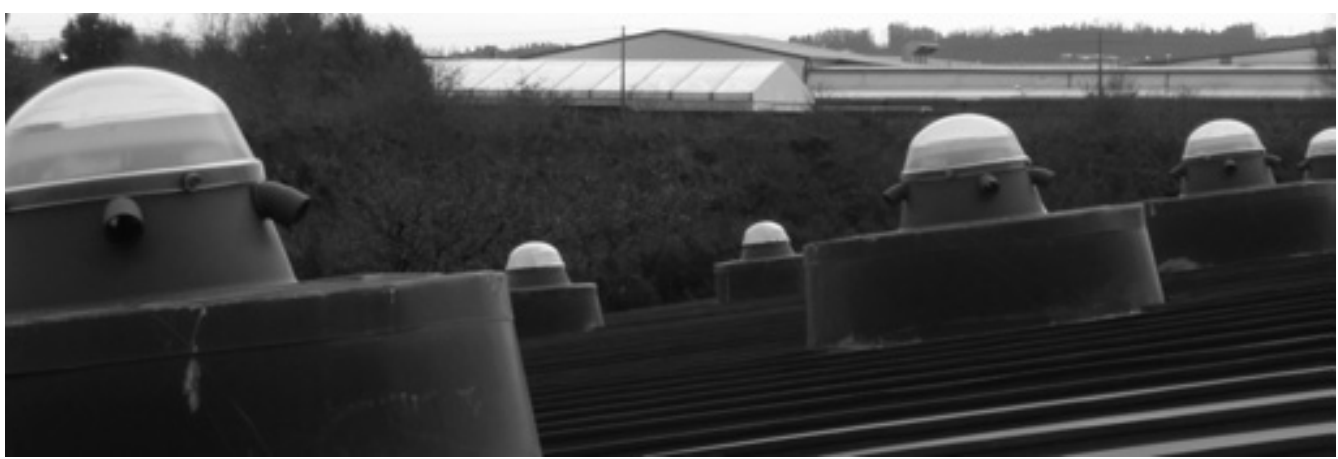

Fig. 8. Lucernarios de las salas de túmulos. Tanatorio de Boisaca. 
grandes maestros es lo que motiva ese deseo de búsqueda para con ello poder dar respuesta a los problemas que se plantean en este tipo de arquitectura.

El conjunto, que fue diseñado, como ya indicaba, teniendo presente en todo momento las características propias del singular uso al que estaba destinado y que tenía que cumplir, —-son "territorios donde la penumbra se hace sombra y la función metáfora" en palabras de Fernández Alba $^{26}$ - y y buscando la sobriedad que debe regir las edificaciones de esta naturaleza, es concebido con una doble vertiente: adaptarse a las necesidades funcionales que exige un edificio de esta naturaleza: salones, despachos, crematorio, capilla, ..., al tiempo que hacerlo con un lenguaje que resultase acogedor para los familiares y acompañantes del difunto, de ahí que todos los elementos que lo componen se articulan y se entienden desde esa perspectiva; de ahí esa arquitectura de espacios abiertos y cerrados, comprimidos y expansivos, como queriendo tener presente nuestro paso por este mundo terreno y como preparación para ese viaje al más allá.

El exterior está concebido con una fachada ventilada con planchas de pizarra brasileña combinada con granito silvestre ${ }^{27}$; un juego de materiales y colores con los que se pretende ratificar la idea que rige su interior, la de ser un espacio tránsito, una "puerta" entre dos ámbitos opuestos (Fig. 9). Dispone de dos cubiertas, una invertida en el espacio transitable y otra formada por chapas de cobre, de esta manera el arquitecto vuelve a retomar la organización interior. Un interior que está revestido con parámetros verticales con pintura plástica acrílica lisa y un revestimiento de papel vinilo para las paredes de las salas de tanatopraxia y tanatoestética. Todo el edificio cuenta con un pavimento de corindón verde sobre solera de hormigón o forjado, con acabado monolítico en los espacios de servicios y de baldosa de gres porcelánico natural para el resto de las dependencias. En el revestimiento de los paramentos verticales interiores se emplearon tableros de madera de Wengéz ${ }^{2}$.

\subsection{La capilla}

Sin lugar a dudas este espacio, que en un primer momento surge como sala de usos múl- tiples, es uno de los elementos más singulares de la edificación. Un recinto que al igual que el resto del tanatorio tiene un diseño limpio, y en el que su relación espacial exterior-interior determina su foco y su significado. El ayuntamiento compostelano, cuando realiza el encargo, pone especial énfasis en que no tenga ningún elemento que pueda relacionársele con lo religioso, y sin embargo desde el mismo momento de su inauguración la sala termina por convertirse en una capilla ${ }^{29}$, mejor dicho, en un espacio multiconfesional que debía acomodarse a la particular identidad de las distintas confesiones, algo necesario no solo por la realidad multirreligiosa que hoy vive nuestra sociedad, sino por ubicarse en un cementerio, de ahí que el arquitecto se vio en la imperiosa necesidad de dejar los muros desprovistos de imágenes, de crear un espacio desnudo, de acogida y meditación y que, aun teniendo un carácter no confesional, lograse crear ese clima necesario que favorece la interiorización y que logra invitar a la reflexión y la meditación, y es que, como decía Fisac, es necesario que:

aquel espacio arquitectónico que va a destinarse al culto sagrado, tenga un no se que transcendente que produzca en los fieles el efecto sensorial de lo Otro, de lo que está fuera de ellos, [...] el arquitecto necesita poner a la iglesia de hoy en contacto [...] con una transcendencia sobrenatura ${ }^{\beta 0}$.

Para conseguirlo Alfredo Varela recurre a proporciones clásicas, en concreto, a proporciones áureas (Fig. 10), con la forma cuadrada como elemento primario, aunque al emplear la diagonal del cuadrado rompe el volumen en dos partes bien diferenciadas que permiten distinguir el área pública de la zona destinada a altar, en la que también recurre a la misma forma áurea primaria y nuevamente con la directriz de la diagonal. Con ello consigue que las aristas de este cuadrado de 285,53 $\mathrm{m}^{2}$ de superficie se transformen en un elemento focal situando en uno de los vértices del cuadrado la puerta de acceso (Fig. 11), que es concebida siguiendo los preceptos del deconstructivismo ${ }^{31}$, y en el extremo opuesto el altar. Con este juego 


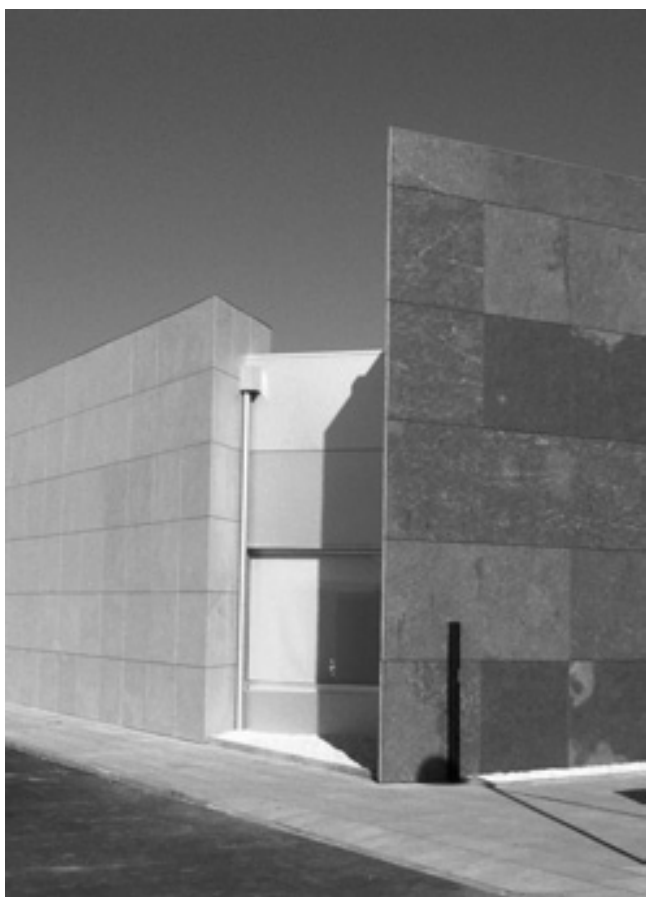

Fig. 9. Detalle de la fachada del tanatorio de Boisaca.

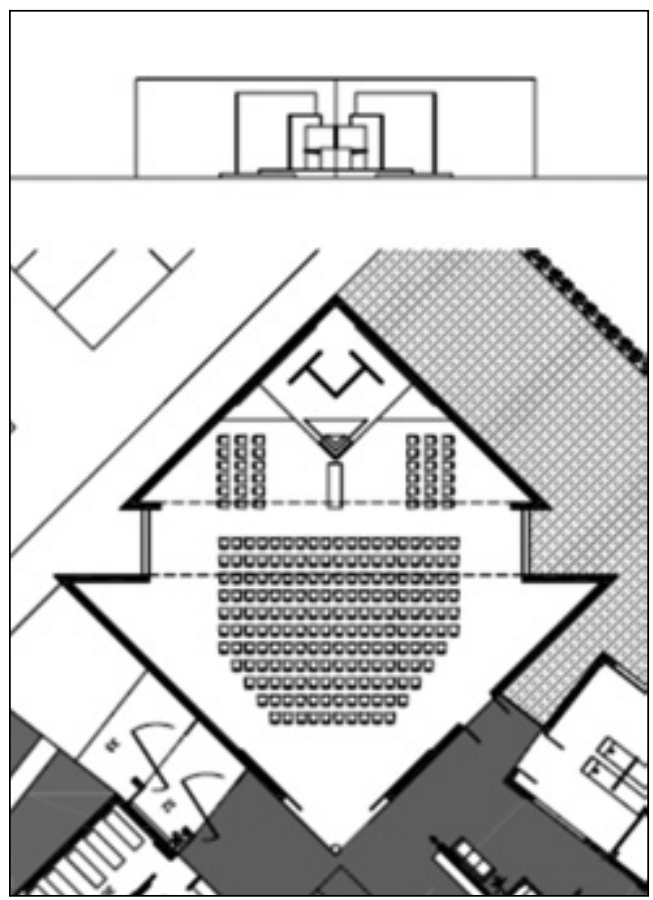

Fig. 10. Planta y alzado de la capilla del tanatorio de Boisaca.

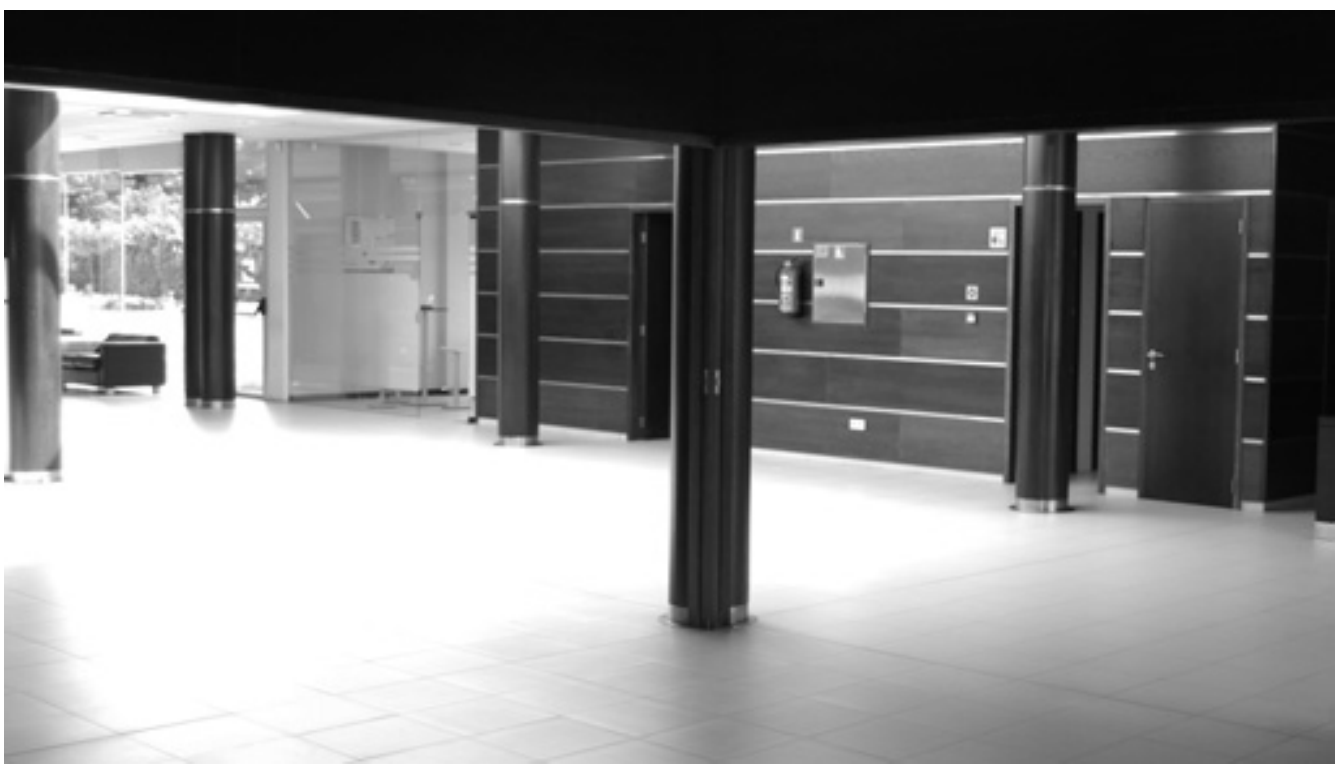

Fig. 11. Puerta de acceso a la capilla del tanatorio de Boisaca. 
de las proporciones áureas rotas por la diagonal se consigue establecer otra figura básica, el triángulo, que en este caso se le puede buscar ya simbología cristiana, una forma geométrica que también adopta la mesa del altar.

Como decía, originariamente nada había en este recinto que nos hablase de que estábamos en un ámbito religioso, y sin embargo, aquel que es creyente y está dotado de una mínima sensibilidad sabrá que se encuentra en una domus ecclesiae, a la que también podemos llamar domus orationis. Surge entonces una arquitectura totalmente distinta, ni antigua ni moderna, una arquitectura que nace al amparo del Concilio Vaticano $\|^{32}$, y es que una iglesia ya no es un lugar con un retablo y con unos altares $^{33}$, sino que es un espacio en donde se reúnen los fieles para la oración, para la celebración de la misa (Fig. 12). Por ello, Varela Nogueira, al igual que ya habían hecho Mies Van Der Rohe, Rafael Moneo o Miguel Fisac, para proyectar ese espacio y hacerlo un lugar sagrado considera que solo requiere los conocimientos técnicos y la sensibilidad del arquitecto. Sabe que el único problema a resolver es crear un recinto apto para la asistencia de los fieles a las distintas prácticas litúrgicas, al tiempo que conseguir que el creyente se sienta muy cercano a lo sobrenatural, se sienta envuelto en un "aire sagrado" que le conmueva, que le lleve a percibir la presencia de Dios ${ }^{34}$; y estoy convencido que este espacio sí emite ese "aire", y lo consigue centrando la atención en el altar, el símbolo más importante de las iglesias ${ }^{35}$ pues en él se celebra la renovación del sacrificio que había tenido lugar en el Gólgota, tanto a través de los elementos constructivos como por el uso de la luz que es la que le proporciona a este espacio austero, desnudo ${ }^{36}$, un sentido místico al remarcar los dos niveles de los que se habló. James Turrell, artista contemporáneo estadounidense que se ocupa principalmente de la luz y el espacio, ha dicho: "La luz no es algo que revela, sino la revelación misma". Se trata de que nos aferremos a ella, no a los objetos que ilumina, por ello necesitamos tiempo para vivir con ella, pensarla, y ver en ella ${ }^{37}$.

La luz es un símbolo tradicional para designar lo inmaterial, lo espiritual, de ahí que siem- pre haya sido una alegoría que nos conduce y relaciona con Dios, y por ello los escritores bíblicos a menudo se refieren a ella usándola como una metáfora de su poder y de su presencia ${ }^{38}, \mathrm{y}$ en el evangelio de san Juan se nos dice que

por ella se hizo todo, y nada llegó a ser sin Ella. Lo que fue hecho tenía vida en ella, y para los hombres la vida era luz. La luz brilla en las tinieblas, y las tinieblas no la impidieron ${ }^{39}$.

Además todavía se siguen conservando en la actualidad muchos detalles del simbolismo de la luz en distintas celebraciones litúrgicas: véase sino el bautismo con la entrega de una vela como la luz de Cristo, y sobre todo la Vigilia Pascual, una función que se celebra la noche del sábado santo y que viene a recordarnos la liturgia bautismal: cuando tras encender el "fuego santo" se prende el Cirio Pascual, y durante la procesión de la Vigilia el celebrante canta por tres veces el "Lumen Christi".

Una luz que será entonces el principal elemento del que se va a valer el arquitecto para darle carácter religioso a este espacio al que accedemos a través de un pasillo limitado por una bancada que pretende simbolizar la "vía sacra" que nos lleva al altar, un camino que conduce al creyente a "la tierra de los vivos". Un altar que se convierte en el elemento significativo de la estancia, ya que en medio de la penumbra en la que se encuentra se resalta una cruz en forma de "tau" incrustada en uno de los paramentos que sirve para crear un espacio que actúa a modo de pequeña sacristía. El efecto conseguido lo considero de lo más acertado, pues además de conseguir una adecuada ambientación lo encuentro dotado de un profundo simbolismo, claro que éste pudiera no entenderse y tener la impresión de que estamos en un lugar un poco artificioso, cuando realmente no se persigue otra cosa más que una elevación espiritual.

El juego de la penumbra del espacio en el que se ubica el túmulo, el "mundo de los muertos", y la luminosidad del que ocupan los acompañantes, gracias a los ventanales de la fachada que proporcionan una luz difusa y envolvente, y 


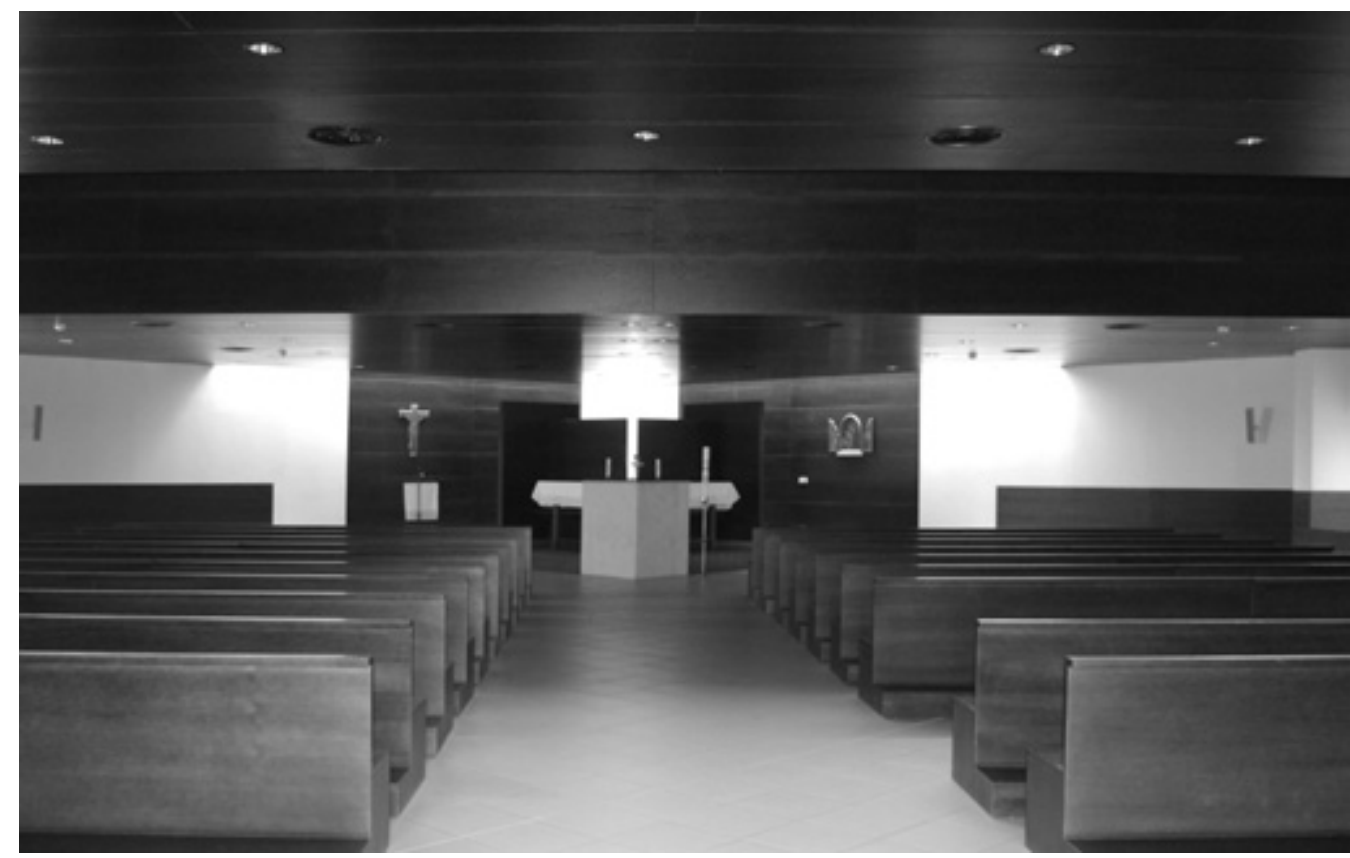

Fig. 12. Capilla del tanatorio de Boisaca.

la luz cenital que penetra por la fisura central acristalada hecha en la cubierta ${ }^{40}$, es algo buscado por el arquitecto de manera consciente y con ello consigue plasmar aquel simbolismo del que nos habla Richard Etlin:

todo un nuevo mundo... en el que el descenso al interior de la tierra, al mismo tiempo abierto al firmamento, nos sitúa en el perfecto espacio de la ausencia ${ }^{41}$.

Una sensación que se incrementa al permitirnos captar fragmentos de cielo y recordarnos su contemplación que la celebración eucarística que en esos momentos se está celebrando es un anuncio del banquete que al creyente le espera en el cielo; es por tanto un elemento dador de vida, una experiencia que resulta aún mas misteriosa si el cielo es azul y las nubes están en movimiento ya que forzosamente nos lleva a recordar la fugacidad de la vida y, en, consecuencia, a la persona ausente.
Y esto será precisamente lo que motiva el que la penumbra sea la que envuelve el espacio en el que tiene lugar la transubstanciación, a diferencia de lo que nos encontramos en la inmensa mayoría de los templos modernos que rompen sus presbiterios para convertirse en auténticos focos lumínicos para así centrar toda la atención del fiel ${ }^{42}$, y es que aquí, además de recordarse el sacrificio del Gólgota, se nos habla del dolor causado por la pérdida y despedida del ser querido. Es esa utilización de la luz y de la oscuridad o "luz negativa" que ya había utilizado el arquitecto visionario neoclásico francés Étienne-Louis Boulleé en su producción funeraria para crear un espacio de ausencia ${ }^{43}$. La materia contra el espíritu y, en su forma más elemental y abstracta, la noción cristiana de separación entre cuerpo y alma, y ese momento de la muerte es lo que aquí precisamente se quiere evocar.

Por supuesto que al hablar del simbolismo de este recinto no voy a entrar en los ingeniosos 
significados de los que nos habla Durand de Mende en su Rational des offices divins ${ }^{44}$. Unos significados de lo más superficiales y que hoy en día tenemos que rechazar, pero no quisiera finalizar sin señalar que el arquitecto con la distribución de la planta que diseña está evocando con esta estancia, desconocemos si consciente o inconscientemente, el mito que todavía pervive en la sociedad de hoy en día, el de la barca de Caronte, la encargada de trasladar al muerto a la otra orilla del río Aqueronte, o la de la laguna Estigia como sugiere Virgilio en su Eneida, sobre todo si después de la celebración litúrgica se da paso a la cremación, proceso al que se accede desde el estribor.

\section{A modo de conclusión}

La muerte, al igual que la vida, exige unos escenarios arquitectónicos exclusivos, unos espacios que han ido variando su morfología en función de la imagen que vamos teniendo sobre la vida y la ausencia de ella, y que se han ido conformando para terminar ofreciendo una arquitectura que olvida la decoración para buscar lo funcional por haber sido concebida con una luz intencionada ${ }^{45}$, por la diafanidad y el minimalismo de los espacios y la recurrencia a materiales puros, de extrema blancura, de modo que la ausencia de una direccionalidad acusada permita al visitante sentir en su dolor el consuelo de cierta libertad y recogimiento, para así poder dar rienda suelta a sus emociones en un marco no condicionante sino aséptico y respetuoso $^{46}$.

Atendiendo a dichos principios, se levanta el tanatorio de Boisaca, que podríamos decir que se caracteriza por lo que denomino "esencialismo", y lo digo porque en él nada falta ni nada sobra, resaltando la expresividad de los materiales, que nos los muestra tal y como son, sin disfrazarlos ni ocultarlos; de las formas y la definición de sus espacios. Los públicos abiertos al paisaje a través de un cerramiento cristalino que permite que el mundo exterior entre a formar parte de la experiencia arquitectónica y, lo que es más importante, contribuya a facilitar las vivencias que tienen lugar dentro del sencillo edificio, cuya construcción estuvo condicionada por un presupuesto reducido. Una peculiaridad que pre- senta un buen numero de tanatorios, entre ellos el de León, en el que también se prioriza la individualidad frente al mundo exterior pero que necesita el contacto con él, algo que se consigue a través de los lucernarios que iluminan el oratorio y las amplias cristaleras de las estancias de espera volcadas hacia los patios interiores. La luz natural y la visión de la naturaleza que rodea y cobija al centro no resultan intrusivas a los sentimientos que se expresan en este tipo de construcciones, sino que relajan y destensan unas instalaciones que, de otro modo, hubieran podido llegar hasta ser molestas.

Esta vinculación con la naturaleza, con una naturaleza entendida como lugar de partida y de retorno, tenemos que verla como algo lógico en unos edificios en los que ya no tiene cabida ese componente específicamente religioso ${ }^{47}$, vinculado a una creencia mayoritaria en el convencimiento de que ésta prima como fe de los usuarios, referencias que nos trasladan a tiempos muy lejanos, cuando las religiones todavía no habían cuajado en el mundo.

El tanatorio municipal de Santiago de Compostela, al igual que la inmensa mayoría de los tanatorios (Carcabuey, Córdoba; Sant Just Baix Llobregat; Castelldefels-Gavà-Viladecans; etc), es concebido como una arquitectura atemporal, despojada de decoraciones superfluas, basada en la mutua potenciación de los espacios y buscando el arquitecto un enfoque funcional, con lo que esta sobriedad, esta sencillez, que no puede ser entendida como pobreza, no está reñida con la belleza, y en la que la luz va a desempeñar un papel primordial. Alfredo Varela deja hablar a la arquitectura y a través de ella nos dice lo mismo que Rafael Moneo en la catedral de Nuestra Señora, de los Ángeles:

entiendo la luz como la protagonista de un espacio que pretende recuperar el sentido de lo trascendente y presentarse como sentido de lo sublime. De ahi que para mi sea la luz vehículo que nos ha de conducir a la experiencia de aquello a lo que llamamos sagrado ${ }^{48}$.

$Y$ es que para representar el "mundo de la ausencia" el hombre se ha valido del símbolo 
construido con dos realidades, luz y materia, junto a una abstracción, el espacio ${ }^{49}$.

Un recorrido por los distintos tanatorios, independiente de los autores o región en la que se encuentren, muestra esa preocupación por hacerlos pertenecer al urbanismo ciudadano, como si fuera uno más de sus equipamientos de modo que, pese a las connotaciones que llevan aparejadas, no caen en la tentación de alejarse de la vida cotidiana, así lo testimonia, por ejemplo, el tanatorio de la M-30 de Antonio Fernández Alba ${ }^{50}$, 1982-84; o los mas tardíos de Bonaduz (Suiza), desarrollado por Rudolf Fontana y Christian Kerez ${ }^{51}$ en 1993, el de Monuta, Apeldoorn (Países Bajos) del estudio Zeinstra Van der Pol ${ }^{52}$, o el de León, proyectado en 1997 por Jordi Badia y Josep Val${ }^{53}$ y finalizado en 2001, que se levanta entre bloques residenciales y que para evitar la dificultad de hacer convivir una edificación con esta finalidad en plena zona urbana, los arquitectos deciden semienterrarlo, una alegoría de su uso, y camuflarlo bajo una cubierta verde en la que sobresalen cubos de cristal y una lámina de agua, en un entorno arbolado, logrando así crear una especie de parque natural. En otros momentos, en cambio, se asienta a las afueras de los núcleos urbanos, como es el caso del de Boisaca ${ }^{54}$, el de Ronda de Arriba (Barcelona), de Hospitalet, de Portugalete, de Torrelavega, de Alcañiz, el de Olivares (Sevilla), o el de Los Arenales (Oviedo), el primero que fue construido fuera de la ciudad, etc.

Hay ocasiones en los que el proyecto se instala en los polígonos industriales como es el caso del de Conil, Cádiz; e incluso podríamos hablar de aquella modalidad que viene determinada por los que son construidos en los cementerios, lo que permitirá a sus autores concebir este espacio como un parque público, un lugar de reflexión, como es el caso del de Alcorcón, o el de "Les Pruelles", en Sitges, diseñado por el estudio de Ribas \& Ribas.

\section{NOTAS}

* Este artículo se ha realizado dentro del proyecto de investigación financiado por la Xunta de Galicia. Consellería de Innovación e de Industria (INCITE 09263131 PR).

1 "La muerte ha sido siempre el reino del eufemismo. La única experiencia de certidumbre que nos queda en el reino de la incertidumbre que nos rodea. Pero la muerte siempre es la de los otros, nunca la nuestra; porque nosotros no nos morimos, se nos mueren nuestros amigos, nuestros familiares, incluso nuestros enemigos". J. L. Pintos, Recorridos por la religión. Akal, Madrid, 2010, p. 21.

${ }^{2}$ Los animales viven sin conocer la muerte mientras que los humanos tenemos conciencia de nosotros mismos como "seres con un fin", lo que explica por qué y como nos ampara- mos en la muerte construyendo todo un sistema protector, como los ritos y las creencias para darnos la ilusión de la eternidad. A. Carloni, "Los espacios de la muerte y sus rituales" en F. J. Rodríguez Barberán (coord.), Una arquitectura para la muerte. I Encuentro internacional sobre los cementerios contemporáneos. Junta de Andalucía, Consejería de Obras Públicas y Transportes, Sevilla, 1993, p. 129.

${ }^{3}$ E. Morin, El hombre y la muerte. Kairós, Barcelona, 1973, p. 9. Citamos por A. Ma ${ }^{a}$, Pérez Naya, "El cementerio rural gallego en las actualidad. Panorámica de una situación", en A. A. Rodríguez Casal y D. L. González Lopo (coord), "Muerte y ritual funerario en la historia de Galicia", en SEMATA. Ciencias Sociais e Humanidades, vol. 17, 2005, p. 542.

${ }^{4}$ M. Fragonara, "Definitivo, ma non troppo", en Rappresentazioni del destino. Immagini della vita e della morte dal XV al XIX secolo nella Raccolta delle Stampe A. Bertarelli. Edizioni Gabriele Mazzotza, Milán, 2001, pp. 51-60.

5 "La cultura gallega, en cuanto cultura vinculada a la tierra ... ha sido una forma permanente de vincularnos a los orígenes y a los fines ... Desde fuera semeja un proceso reiterativo del eterno retorno de lo idéntico, opuesto al 'progreso', al 'cambio', al 'futuro'; siempre inmóvil en la movilidad reiterada de los ciclos de las estaciones, los años y los días. Desde fuera, la naturalización de la muerte aparece como atavismo, atraso, envejecimiento. $Y$ por eso tiene que ser combatida". J. L. Pintos, Recorridos ..., op.cit., p. 21.

${ }^{6}$ Prueba de esta secularización es el elevado número de funerales civiles que en nuestra sociedad se vienen celebrando y que se incrementan de 
año en año, lo que a todas luces evidencia el cambio producido en la creencia del "más allá", al tiempo que el incremento de la práctica de la cremación, algo que la Iglesia católica no acepta hasta 1963.

7 Cierto es que todavía sigue arraigada la costumbre de seguir publicándose múltiples esquelas; esquelas que son pagadas por distintas asociaciones a las que el muerto había pertenecido en vida, o de aquellas instituciones públicas o privadas con las que había estado vinculado durante su existencia, pero, eso si, son cada vez mas frecuentes las que no tienen ninguna referencia religiosa.

${ }^{8}$ Para tener una visión de lo que fue la cultura de la muerte y los muertos en Galicia véase M. Gondar Portasany, Romeiros do alén. Antropoloxía da morte en Galicia. Edicións Xerais, Vigo, 1989, en especial las pp. 69161; y con carácter general Nola, A. M. di, La muerte derrotada. Antropología de la muerte y el duelo. Belacqva, Barcelona, 2007.

${ }^{9}$ Al muerto antes no se le escondía, se le dedicaban numerosos tiempos y ritos, y sobre todo se compartía, era un hecho social profundamente significativo. Así, a decir de Gondar, en la cultura no urbana vivos y muertos constituyen una comunidad, con una interacción que traspasa la vida cotidiana. M. Gondar Portasany, Romeiros do alén..., op. cit., p. 15.

También puede verse M. A. Benítez del Rosario y A. Salinas Martín, Cuidados paliativos y atención primaria. Springer-Verlag Ibérica, Barcelona, 2000, en concreto el capítulo IV, pp. 33-38. [Data de consulta 21/06/2011] http://books.google.es/books?id=kKQ bWoVLQJIC\&pg=PA37\&dq=muerte+ $\% 2 \mathrm{~B}+$ tanatorios\&hl=es\&ei=LQINTo6f NoGUOtWvoaQL\&sa=X\&oi=book_res ult \&ct=result $\&$ resnum $=4 \& v e d=0 C D k$ Q6AEWAzgU\#v=onepage $\& \mathrm{q}=$ muerte $\% 20 \% 2 \mathrm{~B} \% 20$ tanatorios\&f=false y J. A. del Val, El Cristiano de los años 2000. Sal Terrae, Maliaño (Cantabria), 1994, pp. 355-356. [Data de consulta 21/06/2011]http://books.google.es/bo oks? id=rDRZKEI9oRcC\&pg=PA356\&d

$\mathrm{q}=$ muerte $+\% 2 \mathrm{~B}+$ tanatorios\&hl=es\&ei $=$ LQINTo6fNoGUOtWvoaQL\&sa=X\&oi $=$ book_result $\& c t=$ result $\&$ resnum $=7 \& \mathrm{~V}$ ed $=0 C E g Q 6 A E w B j g U \# v=$ onepage $\& q=$ muerte $\% 20 \% 2 \mathrm{~B} \% 20$ tanatorios\&f=false

10 J. L. Pintos, "Tanatorios vs. Velatorios. Las transformaciones de los imaginarios sociales de la muerte en el último decenio", en A. A. Rodríguez Casal y D. L. González Lopo (coord), "Muerte y ritual funerario en la historia de Galicia", SEMATA. Ciencias Sociais e Humanidades, vol. 17, 2005, p. 577; y del mismo autor, Recorridos ..., op.cit., pp. 32-33.

${ }^{11}$ F. Espuelas, "Exitus", Forma y memoria, 18, 2002, p. 36. Cit. por $\mathrm{M}^{\mathrm{a}}$. A. Pérez Naya, "El cementerio rural gallego en la actualidad. Panorámica de una situación", en A. A. Rodríguez Casal y D. L. González Lopo (coord), "Muerte y ritual funerario en la historia de Galicia", SEMATA. Ciencias Sociais e Humanidades, vol. 17, 2005 p. 550.

${ }^{12} \mathrm{H}$. Belting, Antropología de la imagen. Katz Editores, Madrid, 2007, pp. 178-179.

13 Será en 1787, el 3 de abril, cuando una Real Cédula emitida por Carlos III establezca la necesidad de su traslado y alejamiento de los núcleos urbanos: "Se harán los cementerios fuera de las poblaciones, siempre que no hubiese dificultad invencible ó grandes anchuras dentro de ellas, en sitios ventilados e inmediatos á las parroquias, y distantes de las casas de los vecinos; y se aprovecharán para capillas de los mismos cementerios las ermitas que existan fuera de los pueblos". Una disposición que caerá pronto en el olvido, bien por razones económicas o bien por ausencia de azotes epidémicos, ya que una Circular con fecha de 26 de abril de 1804 manda activar, en todo el Reino, "la construcción de cementerios como estaba prevenido, para remediar los funestos efectos que estaba padeciendo el enterramiento en las iglesias y por el respeto y veneración debidos a la casa de Dios", y dos meses más tarde, el 28 de junio, otra Circular va a establecer las bases para la construcción de los camposantos. La respuesta de la ciudad de Santiago de Compostela será nula, a diferencia de lo que sucederá en A Coruña y Vigo. Tenemos que esperar a 1813 para que, previa amenaza de multa, el ayuntamiento compostelano adopte las primeras medidas, pero solo serán eso, primeras medidas, por lo que habrá que esperar a la Real Orden de 22 de noviembre de 1828, y la de 2 de junio de 1833, que seguirá insistiendo en la imperiosa necesidad de la construcción de cementerios y "el enterramiento de los cadáveres en ellos sin condescendencia ni disimulo", para que se plantee actuar. Esta normativa sería olvidada por las autoridades locales hasta enero de 1845, momento en el que el consistorio compostelano, presionado por las autoridades provinciales y ante el grave riesgo que representaba para la salud pública, será cuando establezca los pasos necesarios para su construcción. F. R. Durán Villa, C. M. Fernández Fernández y J. A. Sánchez García, "Asilos de la muerte. Higiene, sanidad y arquitectura en los cementerios gallegos del siglo XIX", en A. A. Rodríguez Casal y D. L. González Lopo, "Muerte y ritual funerario en la historia de Galicia", SEMATA, vol. 17, 2005, pp. 439-451.

${ }^{14} \mathrm{Ph}$. Ariès, El hombre ante la muerte. Taurus, Madrid, 1984, p. 49.

${ }^{15}$ La generalización de la práctica de la incineración, dispuesta de antemano por los vivos para si mismos, y la tendencia de no guardar posteriormente las cenizas en los cementerios sino que estas son aventadas y dispersas muy bien puede motivar que las arquitecturas funerarias no sean ya las destinadas a guardar los restos humanos, en algunos casos verdaderos monumentos arquitectónicos, sino lo sean los tanatorios y los crematorios. ¿A que tipologías arquitectónicas responderán tales edificios?. D. Nicolás Gómez, La morada de los vivos y la morada de los muertos: Arquitectura domestica y funeraria en el siglo XIX en Murcia. Secretariado de Publicacio- 
nes Universidad de Murcia, 1994, pp. 199-200

${ }^{16}$ El primer tanatorio en España surge en 1975, en Irache, Pamplona, y marcará el inicio de una reconversión del sector fúnebre privado en respuesta a las necesidades que demandaba la sociedad.

${ }^{17}$ A partir de un comentario en el que se indicaba que el 2003 había sido un buen año por ser el de mayor número de usuarios podemos decir que "el tanatorio no sólo es un 'servicio' que la comunidad necesita, sino que también es una empresa' que obtiene de su servicio un determinado servicio económico". J. L. Pintos, Recorridos ..., op.cit., p. 33.

${ }^{18}$ Alfredo Varela Nogueira cursa sus estudios en la Escuela Superior de Arquitectura de A Coruña y tiene su estudio en la ciudad de Santiago. Seguidor del hacer de Ludwig Mies van der Rohe, Gunnar Asplund, Alvaro Siza y Rafael Moneo. Entre sus últimas obras cabe citar los edificios de la UMAD, la Concejalía de la Mujer, la Casa de las Asociaciones de Servicios Sociales y el CERSIA, en Santiago de Compostela; la piscina municipal y el Centro Cultural de Negreira (A Coruña). El Centro Deportivo de Jerez de la Frontera, el reacondicionamiento interior del Pabellón Sánchez Paraíso, Salmanca; etc.

${ }^{19}$ Archivo Municipal Santiago de Compostela (A.M.S.C.) Memoria Tanatorio con forno de cremación no cemiterio de Boisaca.

${ }^{20}$ Las condiciones del terreno y el querer hacer compatibles la orientación canónica de la catedral de Nuestra Señora de la ciudad de los Ángeles, y el acceso principal desde una plaza, obliga a Rafael Moneo a situar las puertas del templo lateralmente, ello lleva a la creación de una planta de lo más inusual, en la que las capillas no quedan expuestas a la nave central, abriéndose a sendos deambulatorios que garantizan alcanzar el espacio de la nave tras caminar por ellos. Moneo, Rafael: "Catedral de Nuestra Señora de los Ángeles", en El Croquis, 98 (1999), p.163.
${ }^{21}$ Un criterio similar será utilizado por Jordi Badia y Josep Val cuando en 1999 proyecta el tanatorio municipal de León. Ver "Tanatorio municipal de León", en Quaderns d'arquitectura i urbanisme, 229 (2001), pp. 176-181.

22 San Juan, 8, 12.

${ }^{23}$ Como indica Mumford, en la arquitectura "difícilmente pueden separarse, ni siquiera en un análisis formal, símbolo y estructura, significado y función práctica; pues un edificio, por carente de arte, por inocente que haya sido el discurrir del constructor, no puede evitar decir algo con su sola presencia". L. Mumford, Arte y técnica. Editorial Nueva Visión, Buenos Aires, 1957, p. 88.

24 "El arte se yergue como signo visible de un estado interior de gracia y armonía de exquisita percepción y realzado sentimiento, concentrado e intensificado por la forma misma en la cual el artista traduce su estado interior". L. Mumford, Arte y técnica, op. cit., pp. 23-24.

${ }^{25}$ Miguel Fisac nos dice: "Cada vez estoy más convencido, de que en arquitectura, o se parte del hombre, o sea, o se responde a una necesidad material y espiritual humana o no es arquitectura. Los grandes maestros de la arquitectura contemporánea, nos han enseñado un gran repertorio de formas estéticas, pero creo que se han dejado mucho en el tintero de las necesidades ... en una palabra de la funcionalidad auténtica que deberían tener". M. Fisac, "Necesidad de la belleza en los objetos de uso diario", Arquitectura, 21, septiembre 1960, pp. 29-30. Cit. Ma. C. Morales Saro, La arquitectura de Miguel Fisac. Colegio de Arquitectos, Ciudad Real, 1979, p. 20.

${ }^{26}$ A. Fernández Alba, Reflexiones. Universidad de Navarra, Pamplona, 2005, pp. 14. [Data de consulta 23/06/2011] http://books.google.es/books?id=Pl8E Wjeatw4C\&pg=PA13\&dq=arquitectura $+\% 2 \mathrm{~B}+$ tanatorios\&hl=es\&ei=NKgLTrGT Hs_o-gbagY 3 hDA\&sa =X\&oi=book _result\&ct=result\&resnum $=4 \&$ ved $=0 C D$ ०Q6AEwAzgK\#v=onepage\& $q \& \mathrm{f}=$ false

${ }^{27}$ A.M.S.C. Memoria Tanatorio ...
${ }^{28}$ A.M.S.C. Memoria Tanatorio ...

${ }^{29}$ La Iglesia le pide a los artistas que "al edificar los templos, procúrese con diligencia que sean aptos para la celebración de las acciones litúrgicas y para conseguir la participación activa de los fieles [...], que procuren cuidadosamente los obispos que sean excluidas de los templos y demás lugares sagrados aquellas obras artísticas que repugnan a la fe, a las costumbres y a la piedad cristiana y ofenden el sentido auténticamente religioso, ya sea por la depravación de las formas, ya sea por la insuficiencia, la mediocridad o la falsedad del arte". Concilio Vaticano II. Constituciones. Decretos. Declaraciones. Legislación posconciliar. "Constitución sobre la sagrada liturgia", cap. VII, 123. BAC, Madrid, 1966, p. 239.

${ }^{30} \mathrm{M}$. Fisac, "Algunas consideraciones sobre el espacio arquitectónico sagrado", en Atlántida, n²9-30, septiembre-diciembre 1967, p. 527. Cit $M^{a}$. C. Morales Saro, La arquitectura de Miguel Fisac..., op. cit., p. 23.

${ }^{31}$ El deconstructivismo, también llamado deconstrucción, es un movimiento arquitectónico que surge en los años finales de la década de 1980 . Surge a partir del constructivismo ruso (Alexander Rodchenko y Vladimir Tatlin) y los trabajos de filosofía de Jacques Derrida. Como artistas significativos cabe mencionar a Peter Eisenman, Frank Gehry, Zaha Hadid, Rem Koolhaas, Philip Johnson, Daniel Libeskind, Bernard Tschumi, etc. y como obras significativas el Parque de La Villette, obra del arquitecto suizo Bernard Tschimi en 1982 con la participación de Jacques Derrida y Peter Eisenman; el Museo Guggenheim de Bilbao, de Frank Gehry; El Nederlands Danstheater en la Haya de Rem Koolhaas; la estación de bomberos de Vitra, Alemania, de Zaha Hadid; etc. Ph. C. Johnson, Arquitectura deconstructivista. Gustavo Gili, Barcelona, 1988. J. L. Sanz Botey, Arquitectura del siglo XX. La construcción de la metáfora. Montesinos, Barcelona, 1998, pp. 150 y ss.

32 Tras el Concilio Vaticano II (1962-1965) el templo más que una 
"domus Dei" se convierte en una "domus orationis" o "domus ecclesiae" como otros prefieren llamarle. Ver E. Fernández Castiñeiras, "La primacía de la palabra de Dios en la acción litúrgica. El templo parroquial compostelano en la segunda mitad del siglo XX", en Quintana, n 2 (2003), pp. 267-285.

${ }^{33}$ Miguel Fisac nos habla de la existencia de distintas tendencias de arquitectura religiosa al tiempo que nos expone la que él entendía más adecuada, y que consiste, nos dice: "en restaurar el sentido sobrenatural de la vida cristiana con la visión de nuestro sentido actual de la vida. Es una consecuencia de releer el evangelio, de releer la liturgia [...]. Al expresar arquitectónicamente esta posición, que no es estética, sino religiosa, profunda y auténticamente religiosa, surge entonces una arquitectura totalmente distinta: ni antigua ni moderna, sino nueva, en el que una iglesia no es un lugar con un retablo y con unos altares, sino que es un espacio en donde se reúnen los fieles para la oración, para la celebración de la santa misa, para la adoración eucarística". M. Fisac Serna, "El futuro de la arquitectura religiosa", en Seminarios, 16 (1962), p. 102

34 "... el espacio arquitectónico, que va a destinarse al culto sagrado, tenga un 'no sé qué' trascendente que produzca en los fieles el efecto sensorial de que se encuentra en presencia de lo 'otro', de lo que está fuera de ellos: de Dios [...] El arquitecto necesita poner a la iglesia [...] en contacto sensorial con 'lo otro', con una trascendencia sobrenatural". M. Fisac, "Algunas consideraciones sobre el espacio arquitectónico sagrado", en Atlántida, 1969, pp. 527-530.

${ }^{35}$ Con el mencionado Concilio Vaticano II la Palabra se hace todavía más importante, si cabe, en la Iglesia, al cobrar una relevancia singular, lo que, lógicamente, queda reflejado en lo que podemos llamar "polos de atención", pues ellos serán los puntos destinados a la proclamación de esa
Palabra ante la comunidad de los fieles. Me refiero, claro está, al altar, a la sede y al ambón. La presencia de los dos últimos no tiene aquí justificación al ser una capilla de cementerio. E. Fernández Castiñeiras, "La primacía de la palabra de Dios en la acción litúrgica ...". art. cit., p. 267

${ }^{36}$ Fisac afirma que la principal preocupación que debe tener el arquitecto de hoy en día cuando proyecta una iglesia es la de que sean limpias y sencillas para que así acerquen al fiel a Dios. M. Fisac Serna, "El futuro de la arquitectura religiosa", en Seminarios 16, (1962), p. 102.

${ }^{37}$ A. Zajonc, Atrapando la luz. Historia de la luz y de la mente. Editorial Andrés Bello, Barcelona, 1996, p. 315.

${ }^{38}$ Las primeras palabras que Dios pronuncia al momento de la creación son "hágase la luz" (Génesis 1:3). Se dice de Yahvé que está "arropado de luz como un manto"; "que su fulgor es como una luz; que su Sabiduría es el reflejo de su luz eterna" (SAL. 104,2). Malaquías le había Ilamado "Sol de Justicia" (MALQ. 3,20) y Zacarías "El Sol de lo Alto" (LC.1,78).

${ }^{39}$ San Juan: 1, 3-5.

${ }^{40}$ La ruptura de la techumbre es algo que nos trae evocaciones de Fisac, recordemos, por ejemplo, la iglesia de los PP. Dominicos de Valladolid construida en 1955, aunque ahora sin la utilización de las vidrieras coloreadas.

41 R. Etlin, "El espacio de la ausencia", en F. J. Rodríguez Barberán (coord.), Una arquitectura para la muerte. I Encuentro internacional sobre los cementerios contemporáneos. Junta de Andalucía, Consejería de Obras Públicas y Transportes, Sevilla, 1993, p. 183.

${ }^{42}$ La creación del Universo se inicia con la luz: "Dijo Dios: haya luz, y hubo luz" (Gen. 1, 3). Dios "habita en una luz inaccesible" (1 Tim 6,16). La luz comienza la andadura de la creación, Dios la aparta de las tinieblas y la luz se convierte en símbolo. "Dios es Luz, en Él no hay tiniebla alguna" (Jn $1,5)$. Cristo se define a si mismo como la luz: "Yo soy la luz del mundo, el que me sigue no anda en tinieblas, sino que tendrá la luz de la vida" (Jn. 8, 12). Los cristianos también son luz: "vosotros sois la luz del mundo" (Mt. $5,14)$. No es nada extraño que las Plegarias Eucarísticas, como la 4a. del Misal, alaben a Dios afirmando que Él es "Luz sobre toda luz" y que creó todas las cosas "para alegrar su multitud con la claridad de tu gloria". O, como dice poéticamente el Salmista, "Dios mío, qué grande eres, vestido de esplendor y majestad, arropado de luz como de un manto" (Ps 104,2).

${ }^{43}$ Ver E-L. Boulleé, Architecture, essai sur l'art. Ed. Jean-Marie Pérouse de Montclos, Paris, 1968, pp. 136-137.

${ }^{44} \mathrm{Si}$ leemos a Durand de Mende y su Rational des offices divins nos enteramos de curiosas a la vez que ingeniosas interpretaciones como la de que "las ventanas de la iglesia significan la hospitalidad abierta y la tierna caridad; de que los vitrales representan las Santas Escrituras; de que el pavimento representa el fundamento de nuestra fe a los pobres de espíritu, por su humildad; de que las vigas que unen las distintas partes de la iglesia son los príncipes de este mundo o los predicadores, que defienden la unidad de la Iglesia y la sostienen; de que las sillas del coro son los emblemas de las almas contemplativas; de que la sacristía, donde se dejan los vasos sagrados, es el seno de Bienaventurada Virgen María, etc.". J. Hani: El simbolismo del templo cristiano. Olañeta, Palma de Mallorca, 1997, p. 15.

45 Los tanatorios van a estar caracterizados por estar dominados por la luz, por una luz llena de simbolismo, y en el que las claraboyas nos hablan de la presencia del cielo y los huecos abiertos en unos muros que se desmaterializan quieren subrayar e vínculo del edificio con la tierra. J. F. Gonçalves: "Capillas funerarias, Oliveira (Portugal)", AV: Monografias. Recintos religiosos, 95, mayo junio (2002), p.8.

${ }^{46}$ L. Muñoz Pérez: "De la construcción reciente para el eterno des- 
canso. La arquitectura mortuoria en la actualidad", De Arte, 9, 2010, p. 224.

${ }^{47}$ Las soluciones que nos ofrece este tipo de arquitectura responden a un mismo fin, satisfacer las necesidades demandadas por la sociedad actual, y quizás a ello obedezca el hecho de que hasta sea poco frecuente la presencia muy visible de la cruz en los oratorios (hay incluso tanatorios como el de Monuta en Apeldoorn, Países Bajos, que carecen de este tipo de recintos), cuando, queramos o no, estamos en un espacio "religioso", y es que se busca no hacer demasiado explícita la presencia de la religión cris- tiana, de una deliberada ambigüedad, es como si se pretendiese estar en una tierra de nadie.

${ }^{48}$ R. Moneo, "Catedral de Nuestra Señora ..." art. cit., p. 166.

${ }^{49}$ A. Fernández Alba, Reflexiones, op. cit., p. 14

50 J. D. Fullaondo: "Meditaciones en el espacio de la arquitectura, Anthropus, 152 (1994), pp. 57-61.

51 Ch. Kerez: "Tanatorio Bonaduz", 2G: revista internacional de arquitectura, 14 (2000), pp. 16-21.

52 Atelier Zeinstra Van der Pol: "Tanatorio de Monuta, Apeldoorn
(Países Bajos)", AV: Monografias. Recintos religiosos, 95, mayo junio (2002), pp. 102-107.

53 J. Badia y J. Val Revista: "Tanatorio Municipal de León", On diseño, 227 (2001), pp. 252-263.

${ }^{54}$ El tanatorio de Boisaca, al igual que sucede con otros tanatorios situados en las afueras de las ciudades, como, por ejemplo, el de Sant Joan Despí, se sitúa al lado mismo del cementerio, aunque está pensado para que en el momento en el que las necesidades obliguen a su ampliación forme parte del mismo. Se presenta así como un juego de contrarios. 